\title{
The relationship between family environmental factors and child sensory integration
}

\author{
Jun Zhang*1, Mude Tang ${ }^{2}$ \\ ${ }^{1}$ Faculty of Nursing, School of Health Sciences, Wuhan University, Wuhan, China \\ ${ }^{2}$ Department of Rehabiliation, The Disabled Persons Federation of Guangdong Province, Guangzhou, China
}

Received: June 11, 2019

DOI: $10.5430 /$ jnep.v10n1p16
Accepted: September 2, $2019 \quad$ Online Published: September 18, 2019

URL: https://doi.org/10.5430/jnep.v10n1p16

\begin{abstract}
Objective: To investigate the relationship between child sensory integration and family environmental factors.

Methods: This was a cross-sectional study. The sample $(\mathrm{n}=130)$ was recruited from children attending the outpatient department of a pediatric hospital located in central part of China. Sensory integration of the child was reported by either parent from using a Chinese version of the Sensory Integration and Praxis Test.

Results: Approximately $17.69 \%-24 \%$ of the participating children experienced impairments in different dimensions of sensory integration. Severe impairment occurred in 3\%-5\% of the participating children. Paternal-child interaction had a significant effect on vestibular function of the child, after controlling for the effect of covariates including maternal obstetric history and low birth weight status of the child. Family functioning was found significantly related to tactile sensation, proprioception. and learning ability of the children.

Conclusions: It appears that family environment plays a significant role in sensory integration outcomes of older children.
\end{abstract}

Key Words: Child, Family environment, Sensory

\section{INTRODUCTION}

Sensory integration (SI) refers to brain functionality whereby the nervous system manages incoming sensory information and allows the body to produce adaptive movement or behavior. ${ }^{[1,2]}$ Normal SI is the prerequisite for children to process and integrate sensory information in order to develop body awareness in space as well as interact effectively with the environment. ${ }^{[3]}$ Sensory integration dysfunction can be classified into two different patterns including poor sensory modulation and poor praxis. ${ }^{[4]}$ Children with poor sensory modulation may demonstrate exaggerated or inappropriate responses to everyday sensory input. ${ }^{[4]}$ Poor praxis is characterized by difficulty in organizing and carrying out a novel motor performance or acting on the environment. ${ }^{[4]}$
Sensory integration dysfunction is a common characteristic associated with a number of child developmental and behavioral disorders (i.e. Autism Spectrum Disorder, child anxiety disorder). ${ }^{[5,6]}$

Family environment as a primary social microsystem tends to emphasize an individual's role and relations in the immediate setting containing the individual. ${ }^{[7]}$ The family in its most common form is a lifelong commitment between mother and father who feed, shelter and nurture their children until they reach maturity. As a primary socialization context, family is considered to be very important for child development. ${ }^{[8]}$ There is an established link between family environmental factors (i.e. low-income status, severe inter-

*Correspondence: Jun Zhang; Email: catherinezhang2010@126.com; Address: School of Health Sciences, Wuhan University, Wuhan, China. 
parental discord) and child psychological problems such as child anxiety. ${ }^{[9,10]}$ However, the role of family environment on child SI developmental outcome is rarely mentioned in the literature.

\subsection{Sensory integration}

Sensory integration theory addresses the relationship between brain and behavior. Sensory integration is a theoretical framework widely used by pediatricians and occupational therapists to understand the underlying causes of child learning, behavioral or developmental problems. ${ }^{[11]}$ It lays the foundation for high-level cognitive, motor and social development. $^{[12]}$ Sensory integration theory or framework continually evolves due to the complexity and controversy of the construct of SI. Ayres originally defined SI as "the ability to organize information for use". ${ }^{[13]}$ The definition was further expanded to include information processing, where the brain receives, interprets and integrates sensory inputs from different sensory modalities. In order to adapt to the changing environment, SI requires functioning in a flexible and constantly changing pattern. ${ }^{[1]}$ SI theory contains three major components including the description of normal integrative SI, the definition of sensory integrative disorder, as well as guidance in SI intervention. Learning depends upon the child's ability to take in sensory information from the external environment and their body movement, and the ability to interpret, process and use the information to plan and organize behavior. Deficits in SI can lead to difficulty in conceptual and motor learning. Proper sensory stimulus may help with the maturation and development of a child's SI, which may further lead to enhanced learning performance. ${ }^{[4]}$ Nowadays sensory-based therapy has been increasingly used by occupational therapists in treating children with developmental and behavioral disorders. ${ }^{[14]}$ The therapy includes activities that help the sensory system to organize vestibular, proprioceptive, auditory, and tactile inputs, through the use of specially designed therapeutic equipment (i.e brushes, swings, and balls). Relevant therapy strategies have been accepted as one major component of a comprehensive treatment plan, although relevant research evidence regarding their effectiveness is limited and inconclusive. ${ }^{[15]}$

Sensory integration begins with fetal development and continues through infancy and early childhood. Most fundamental abilities of SI mature by 7 or 8 years of age. ${ }^{[12]}$ Currently the diagnostic framework of sensory integrative disorder is not standardized and hence the disorder has not been included in the Diagnostic and Statistical Manual of Mental Disorders (DSM)-V. ${ }^{[16]}$ Although the disorder has been heavily researched in occupational therapy, it has not been substantively integrated into clinical practice including that of nurs-

Published by Sciedu Press ing practitioners. ${ }^{[17]}$

\subsection{Influencing factors of SI development}

According to the study of Lin et al. (2013), age was a significant predictor for various stages of SI development. Children in older age groups demonstrated better performance on postural movement, sensory discrimination, sensory seeking, attention and activity than those in younger groups. ${ }^{[18]}$

Children with certain perinatal risks (i.e. pre-term, low birth weight, brain injury) were more likely to develop problems with SI. ${ }^{[19,20]}$ In a study of Van Hulle et al. (2015), typically developing twins $(\mathrm{N}=978)$ were recruited and their sensory over-responsivity was measured at age 2 and 7 . Based on risk status of sensory outcomes at age 2 and 7, the sample was divided into four trajectory groups including low symptom, remitting, late-onset and chronic. Children in the chronic group tended to deliver at low birth weight and at younger gestational age than those in the low symptom group. It was found that sensory over-responsivity is likely induced by different developmental causes and etiologies. ${ }^{[21]}$

According to Wilbarger et al. (2010), children with experience of prolonged institutionalized care demonstrated higher levels of sensory reactivity and showed more aversion to sensory stimuli, when compared to children who were adopted early and primarily from foster care or those who were raised by birth parents. Therefore, sensory and social deprivation might contribute to future child sensory problems. ${ }^{[22]}$

Liu et al. (2002) investigated a total of 1,526 children aged from 3-6 years from 15 kindergartens and found that parental rejection was a significant influencing factor of SI development. ${ }^{[23]}$ Previous literature regarding influencing factors of sensory integration development is limited and inconsistent. These factors were either related to a child's own stage of development or risk factors associated with pregnancy or birth. Meanwhile some types of families may pose more risks to children than other types. Previous literature has tended to focus on children under 3 years of age.

\subsection{Study aims}

The specific aim of the study was to investigate whether family environmental factors were significantly associated with child SI development.

Specific research questions were:

(1) What was the the status of SI in children over 3 years of age, including their level of SI and percentage of SI impairments?

(2) Were SI outcomes of the children significantly related to family environmental factors including family functioning, parental education, parental interaction with the child, and 
family socioeconomic status (SES)?

\section{Methods}

\subsection{Sample and setting}

The study was conducted in a tertiary pediatric health care center located in Wuhan, central part of China. Convenience sampling was used to recruit 130 parent-child dyads from the outpatient department between Apr 2013 to Mar 2014.

The inclusion criterias were: 1) Parents (mother and/or father) accompanying their child for a medical visit to the outpatient clinic of the pediatric health care center; 2) Parents having resided in the same geographic region for at least 5 years; 3) Parents are able to read, write, and comprehend Chinese, and have no difficulty in completing written questionnaires. 4) Children with chronic medical diseases (i.e. renal disease, asthma, blood disorder et al.) attended the medical clinics for regular follow up. Exclusion criteria included: 1) Children younger than 3 years age; or having a history of neurological disease, genetic disorders or psychiatric conditions; 2) Parents having a history of psychiatric conditions, or are illiterate or unwilling to cooperate with the researcher. 3) Parents residing in the city or surrounding area for less than 5 years.

\subsection{Data collection procedure}

Eligible parent-child dyads were approached by a research assistant in the waiting room, where a brief introduction about the study purpose and procedure.were provided. The parents who agreed to participate in the study were provided with informed consent and a set of self-report tools to fill out. Parents were given brief guidance about how to complete the following questionaires. The entire process took about 10-15 mins.

\subsection{Measurement tools}

1) Child Sensory Integration Scale: This scale was developed by a Taiwanese psychologist, with items modified from the Sensory Integration and Praxis Test. The scale was introduced to mainland China by researchers at the Beijing Medical University Institute of Mental Health (changed to Beijing University Institute of Mental Health in 2000). ${ }^{[24]}$ It contains 58 items, each scoring on a 1-5 Likert scale. The four dimensions include: (1) motor balance and major muscle function (vestibular sense) which is the awareness of the position of one's head in relation to gravity and movement which is used to come down a slide, or ride a playground swing without falling off; (2) tactile defense and emotional instability including an over response to being touched which might be associated with an underlying emotional problem; (3) proprioception: the internal awareness of the position of one's joints and muscles in space which allows an individual to lift a spoon to the mouth without spilling a liquid; (4) learning deficits including a lack of adequate learning function due to problems in visual perception or visual motor perception.

A fifth dimension, special problems of older children, was only assessed for those older than 11 years of age. The scale had established reliability and validity in a Chinese setting. The test-retest reliability was .47-.73, split-half reliability was .68-.77, and Cronbach's $\alpha$ was .44-.63, the concurrent validity was .49-.94. ${ }^{[24,25]}$

2) Family APGAR index: This scale was developed by Smilkstein from the University of Washington and consists of five dimensions of family functioning, including A (Adaptability), P (Partnership), G (Growth), A (Affection), and R (Resolve). The response options are set to describe perceptions about family relationships on a 3-point scale from 0 (hardly over) to 2 (almost always). The scale can be completed in less than 5 minutes. Cronbach's $\alpha$ of the scale ranged from .80 to $.85 .^{[26]}$

3) Self-designed questionnaire: This was developed by the research team and used to obtain demographic characteristics of the participants, perinatal and family environmental factors including family income and parental education level. The interaction between parent and child was assessed by a single item "How often did you interact with your child?". Perinatal factors including maternal history of pregnancy and delivery, and preterm birth and low birth weight status of the child were reported by the parents.

\subsection{Data analysis}

Mean, standard deviation (SD) and percentage were used to describe the distribution of sample characteristics such as age, family income, maternal history of pregnancy and delivery. Pearson's r or Chi-square test was used to identify the relationship between SI, its subscales, and family environmental factors. Stepwise multiple linear regression was used to identify the effect of family environmental factors on SI, after controlling for the effect of perinatal factors including maternal obstetric history and low birth weight. The default criteria of $\mathrm{F}$ for variable entry is $<.05$ and $>$. 1 for variable removal.

\subsection{Ethical considerations}

Permission to conduct the study was obtained from the research ethics office of the hospital and the university where the first investigator was employed. Participants' identity (i.e name, address) did not appear on the data collection forms; their confidentiality was maintained throughout the study. All data were collected anonymously and only accessible 
to the research team and the participating parents signed the informed consent before data collection was initiated. Potential risks of the study were minimal, despite time and energy involvement of the parents. Since the study was done as part of a developmental check-up, parents tended not to worry about the results. Researchers emphasized that parents could withdraw from the study at any time without posing any consequences to their children's medical care. Data were stored in a password-protected computer and only accessible to the research team.

\section{RESUlts}

\subsection{Characteristics of participating children or families}

The descriptive characteristics of the participants are shown in Table 1 and Table 2. There were 61 (46.92\%) male children and $69(53.08 \%)$ female. Children ranged in age from $3-11$ years, with half $(49.23 \%$ ) of them being under 6 (not attending primary school). About $17.69 \%$ were pre-term. Mean birth weight was $3.37 \mathrm{~kg}(\mathrm{SD}=0.64)$. Approximately $17.7 \%$ of the mothers had experienced an abnormal pregnancy (i.e. hypertension of pregnancy), 16.9\% experienced an abnormal labor (i.e. prolonged duration), and around $10 \%$ of the mothers had a history of delivery complications.

Table 1. Characteristics of participating children $(n=130)$

\begin{tabular}{lllll}
\hline & N & \% & Mean & Sd \\
\hline $\begin{array}{l}\text { Age range (years) } \\
<6(3-5)\end{array}$ & 64 & 49.23 & 6.30 & 2.66 \\
$\geq 6(6-11)$ & 66 & 50.77 & & \\
Gender & & & & \\
Male & 61 & 46.92 & & \\
Female & 69 & 53.08 & & \\
Birth weight (kg) & & & 3.37 & 0.64 \\
Gestational age & & & & \\
$<37$ weeks & 23 & 17.69 & & \\
$37-42$ weeks & 101 & 77.69 & & \\
$>42$ weeks & 6 & 4.61 & & \\
\hline
\end{tabular}

According to Table 2, about $46.92 \%$ of the mothers were high school graduates and $26.92 \%$ were college graduates. Around $43 \%$ of the fathers graduated from college. Eighty percent of the mothers reported having often or always interaction with their child; however, the types of interactions only occurred in $50.77 \%$ of the fathers. Approximately $46.15 \%$ of the participating families had an annual income between 50,000-100,000 RMB.

The mean score of family functioning was $14.56(\mathrm{sd}=4.25)$. Normal functioning occurred in $53.85 \%$ of the participating families with the rest being either mildly impaired or severely impaired.

Published by Sciedu Press

\subsection{Sensory integration level}

According to Table 3, most children in the sample had a normal value of SI. Approximately $24 \%$ of the sample had impairments (respective SI subscale score was less than 40) on vestibular function, $17.69 \%$ on tactile defensiveness, $22.30 \%$ on proprioception, and $24.24 \%$ on learning ability. Severe impairment (SI subscale score less than 30) occurred in 3\%$5 \%$ of the children. According to Table 4, gender was a significant influencing factor of overall SI score. Female children exhibited lower rates of learning ability impairments than male children $(p=.44)$.

Table 2. Family environment characteristics of the sample

\begin{tabular}{ll}
\hline & N (\%) \\
\hline Maternal education & $34(26.15)$ \\
Not graduate from high school & $61(46.92)$ \\
High school graduates & $35(26.92)$ \\
College graduates & \\
Interaction between mother and child & $35(26.92)$ \\
Always & $69(53.08)$ \\
Often & $19(14.62)$ \\
Sometimes & $6(4.62)$ \\
Occasionally & $1(.76)$ \\
Rarely & \\
Paternal education & $33(25.38)$ \\
Under high school & $41(31.54)$ \\
High school graduates & $56(43.08)$ \\
College graduates & \\
Interaction between father and child & $17(13.08)$ \\
Always & $49(37.69)$ \\
Often & $47(36.15)$ \\
Sometimes & $16(12.31)$ \\
Occasionally & $1(.77)$ \\
Rarely & \\
Family functioning & $70(53.85)$ \\
Good & $45(34.61)$ \\
Mild impairment & $15(11.54)$ \\
Serious impairment & $10(7.69)$ \\
Annual family income & $34(26.15)$ \\
20,000 to 50,000 & $60(46.15)$ \\
50,000 to 100,000 & $23(17.69)$ \\
More than 300,000 & $3(2.32)$ \\
\hline
\end{tabular}

\subsection{The relationship between family environmental fac- tors and SI}

As seen in Table 5, there was a significantly positive association between family income and child learning ability $(r=$ $.315, p=.010)$, suggesting that children from higher income families had better learning ability than those from lower income families. Family functioning was related to three subareas of SI including tactile sensation, proprioception, and learning ability $(r=.219, p=.017 ; r=.271, p=.003$ 
and $r=.405, p=.001$, respectively). Interaction between the father/mother and child was found to be significantly associated with child vestibular function and tactile sensation. There was a medium-degree association ( $r$ ranging from $.31-$ .41) between learning ability and three family environmental factors including family income, family functioning, and maternal education. This suggested that children tend to have better learning ability if raised by more educated, and capable parents, and families with a higher income.

Table 3. Sensory integration level of the sample $(n=130)$

\begin{tabular}{lllll}
\hline & $\begin{array}{l}\text { Vestibular Function } \\
\mathbf{n = 1 3 0}\end{array}$ & $\begin{array}{l}\text { Tactile Sensation } \\
\mathbf{n = 1 3 0}\end{array}$ & $\begin{array}{l}\text { Proprioception } \\
\mathbf{n = 1 3 0}\end{array}$ & $\begin{array}{l}\text { Learning Ability } \\
\mathbf{n}=\mathbf{6 6}\end{array}$ \\
\hline Good ( $\geq$ 40) & $99(76.15)$ & $107(82.31)$ & $101(77.70)$ & $50(75.76)$ \\
Mild impairment (30-40) & $26(20.00)$ & $16(12.31)$ & $22(16.92)$ & $14(21.21)$ \\
Serious impairment $(<\mathbf{3 0})$ & $5(3.85)$ & $7(5.38)$ & $7(5.38)$ & $2(3.03)$ \\
Total Score & & & & \\
Mean & 49.08 & 49.44 & 49.65 & 49.90 \\
Sd & 11.02 & 12.01 & 11.26 & 11.38 \\
\hline
\end{tabular}

Table 4. The association of gender and different types of sensory integration using Chi-square

\begin{tabular}{|c|c|c|c|c|c|c|c|c|}
\hline \multirow{2}{*}{ Gender } & \multicolumn{2}{|c|}{ Vestibular function } & \multicolumn{2}{|c|}{ Tactile sensation } & \multicolumn{2}{|c|}{ Proprioception } & \multicolumn{2}{|c|}{ Learning ability } \\
\hline & Good & Dysfunc & Good & Dysfunc & Good & Dysfunc & Good & Dysfunc \\
\hline Male & 43 & 18 & 49 & 12 & 48 & 13 & 17 & 10 \\
\hline Female & 56 & 13 & 58 & 11 & 53 & 13 & 33 & 6 \\
\hline$\chi^{2}$ & 2.029 & & .309 & & .051 & & $4.073^{*}$ & \\
\hline$p$ & .154 & & .578 & & .822 & & $.044 *$ & \\
\hline
\end{tabular}

Table 5. Pearson correlation coefficient between sensory integration and family environmental factors

\begin{tabular}{|c|c|c|c|c|c|c|}
\hline Risk factors & Factor 1 & Factor 2 & Factor 3 & Factor 4 & Factor 5 & Factor 6 \\
\hline \multicolumn{7}{|c|}{ Vestibular function } \\
\hline$r$ value & .100 & .169 & .002 & .059 & $.255^{* *}$ & $.290 * *$ \\
\hline$p$ & .256 & .066 & .986 & .514 & $.003 * *$ & $.001^{* *}$ \\
\hline \multicolumn{7}{|c|}{ Tactile sensation function } \\
\hline$r$ value & .076 & $.219 *$ & .035 & .052 & $.179 *$ & .136 \\
\hline$p$ & .388 & $.017 *$ & .694 & .560 & $.042 *$ & .124 \\
\hline \multicolumn{7}{|c|}{ Proprioception } \\
\hline$r$ value & .165 & $.271^{* *}$ & $.195 *$ & .173 & .165 & .025 \\
\hline$p$ & .061 & $.003^{* *}$ & $.028 *$ & .052 & .061 & .776 \\
\hline \multicolumn{7}{|c|}{ Learning ability } \\
\hline$r$ value & $.315^{* *}$ & $.405^{* *}$ & .239 & $.353^{* *}$ & .234 & .098 \\
\hline$p$ & $.010^{* *}$ & $.001^{* *}$ & .059 & $.005^{* *}$ & .059 & .434 \\
\hline
\end{tabular}

Note. Factor 1 = Family income; Factor 2 = Family functioning; Factor 3 = Paternal education background; Factor 4 = Maternal education background Factor 5 = Paternal interaction with the child; Factor 6 = Maternal interaction with the child; ${ }^{*} p<.05 ; * * p<.01$.

The univariate analysis results indicated that all family environmental factors were significant influencing factors of at least one SI subarea. Therefore, all entered the stepwise multiple regression model. Table 6 shows the influence of family environmental factors on SI after controlling for the effect of covariates including maternal obstetric history and low birth weight status of the child. Results found that paternal-child interaction had a significant effect on vestibular function of the child. Family functioning was also found to be significantly related to tactile sensation, proprioception, and learning ability of children. Family functioning accounted for $16.5 \%$ of the total variance in child learning ability. 
Table 6. Effect of family environmental factors on child sensory integration using step-wise multiple regression

\begin{tabular}{|c|c|c|c|c|c|c|c|}
\hline & $\mathbf{B}$ & $\mathbf{S E}$ & $\bar{\beta}$ & $\overline{R^{2}}$ & Adjusted $R^{2}$ & $\mathbf{F}$ & $p$ \\
\hline \multicolumn{8}{|c|}{ Vestibular function } \\
\hline Model 1 & - & - & - & \multirow{3}{*}{.085} & \multirow{3}{*}{.077} & \multirow{3}{*}{10.450} & \multirow{3}{*}{$.002 *$} \\
\hline (Constant) & 57.901 & 2.892 & - & & & & \\
\hline Factor 7 & -3.580 & 1.108 & -.292 & & & & \\
\hline \multicolumn{8}{|c|}{ Tactile sensation } \\
\hline Model 2 & - & - & - & \multirow{3}{*}{.051} & \multirow{3}{*}{.043} & \multirow{3}{*}{6.036} & \multirow{3}{*}{$.016^{*}$} \\
\hline (Constant) & 40.083 & 4.015 & - & & & & \\
\hline Factor 4 & .647 & .263 & .226 & & & & \\
\hline \multicolumn{8}{|c|}{ Proprioception } \\
\hline Model 3 & - & - & - & \multirow{3}{*}{.066} & \multirow{3}{*}{.057} & \multirow{3}{*}{7.879} & \multirow{3}{*}{$.006^{*}$} \\
\hline (Constant) & 39.041 & 3.805 & - & & & & \\
\hline Factor 4 & .701 & .250 & .256 & & & & \\
\hline \multicolumn{8}{|c|}{ Learning ability } \\
\hline Model 4 & - & - & - & \multirow{3}{*}{.179} & \multirow{3}{*}{.165} & \multirow{3}{*}{12.663} & \multirow{3}{*}{$.001 *$} \\
\hline (Constant) & 31.887 & 4.892 & - & & & & \\
\hline Factor 4 & 1.148 & .323 & .423 & & & & \\
\hline
\end{tabular}

Note. Factors 4 = family functioning; Factor 7 = paternal interaction with the child.

\section{Discussion}

\subsection{Discussion of the results}

In this sample, the percentage of mild impairment on vestibular function, tactile sensation, proprioception, and learning ability were $26 \%, 16 \%, 22 \%$ and $14 \%$, respectively. The percentage for severe impairment was $5 \%, 7 \%, 7 \%$ and $2 \%$, respectively. These results were slightly higher than those of a recent study conducted in China, where among 2,515 children aged 4-6 years, approximately $24 \%$ had mild impairment and $1.4 \%$ experienced severe impairment on sensory processing. ${ }^{[27]}$ This might be because the current study sample was recruited from a pediatric health center rather than from the general population.

The study results showed that male children were at higher risk for poor learning ability than female children. Results were in accord with previous study findings of $\mathrm{Yu}$ et al. (2006), where a significant difference in SI was found between male and female children. Males were more likely to experience SID than females, especially in vestibular function. ${ }^{[28]}$ The gender disparity could be because male children tended to develop slower in sensory function than female during school ages. ${ }^{[23]}$

Results indicated that parental interaction with the child was important for child vestibular function and tactile sensation. Coster and Haley (1992) emphasized the need to consider the interactions between children and their families or caregivers and to design interventions to address the needs of children within the broader context of family, home, school, and other environments in which children participate. ${ }^{[29]}$ Numerous study results have demonstrated that limited social interac- tions, exploration, and play could lead to child developmental delay, growth delay, social behavioral problems, and attention and activity problems. ${ }^{[30-32]}$ Children who lived in a single family or a stepfamily were vulnerable to SID. ${ }^{[23,28]}$ Children raised in an orphanage usually lacked consistent physical, social, and emotional care as provided by mothers, therefore they were at high risk for child developmental delays. ${ }^{[33]}$

This study found that family functioning had significant impact on child tactile sensation, proprioception, and learning function. This was similar to the study results of Liu et al., which found that maternal rejection was a significant predictor of sensory integrative dysfunction. Rejection from parents could lead to a child's low self-esteem and lack of creativity. ${ }^{[23]}$ In this study, children's learning abilities were found to be associated with family income. Child learning ability and proprioception level were found to be related to parental educational level. According to Duncan and BrooksGunn (1997), children in families with low incomes are at greater risk of poor cognitive, health, and social outcomes than children in families with high incomes. ${ }^{[34]}$ Children from resource-limited families lacked the opportunity to be exposed to environmental complexity with regard to sensorymotor experiences. ${ }^{[35,36]}$

Previous study results have demonstrated the negative impact of perinatal factors on SI development. ${ }^{[37]}$ The rate of SID in children who were delivered by cesarean section was higher than those born by vaginal delivery. ${ }^{[38]}$ Gestational age could explain 5\% of the variance in tactile sensitivity. However, these results were not supported by the current study. 


\subsection{Limitations}

Two limitations were noted in the present study. The sample was limited to an urban setting and thus the results might not be generalizable to children living in rural areas. The results provide minimum evidence of a causal association between family environment and child SI. Other research methodologies such as a prospective cohort study, should be considered in the future to serve this purpose.

\subsection{Recommendations}

Study results indicated that child SI outcomes were likely affected by family contextual factors, particularly family functioning and family SES. It is recommended that proper interventions should be developed in order to target these vulnerable families. The development of SI interventions requires interdisciplinary efforts from pediatricians, nurses, occupational therapists, and family members. Routine screening for SI deficits needs to be integrated into pediatric health care practice in outpatient and primary care settings.

\section{ACKNOWLEDGEMENTS}

The authors are grateful to Yun Hua for her coordination in data collection process. Sincere thanks are extended to all participating parents and their children, as well as all staff members working at the hearing screening clinic of the hospital.

\section{CONFLicts OF InTEREST Disclosure}

The authors declared no conflicts of interests.

\section{REFERENCES}

[1] Mailloux Z. An overview of Sensory Integration and Praxis Tests. Am J Occup Ther. 1990 Jul; 44(7): 589-94. PMid:2386185 https : //doi.org/10.5014/ajot.44.7.589

[2] Parham LD, Roley SS, May-Benson TA, et al. Development of a fidelity measure for research on the effectiveness of the Ayres sensory integration intervention. Am J Occup Ther. 2011; 65(2): 133-42. PMid:21476360 https://doi.org/10.5014/ajot.2011.0007 45

[3] Ayres AJ, Mailloux Z. Influence of sensory integration procedures on language development. Am J of Occup Ther. 1981; 35(6): 383-90. PMid:6166198 https://doi.org/10.5014/ajot.35.6.383

[4] Bundy AC, Lane SJ, Murray EA. Sensory integration theory and practice.2nd ed. Philadelphia, PA.: FA Davis Company; 2002.

[5] Faller P, Hunt J, van Hooydonk E, et al. Application of datadriven decision making using Ayres sensory integration with a Child with autism. Am J. Occup Ther. 2016; 70(1): 7001220020p1-9. PMid:26709422 https://doi.org/10.5014/ajot.2016.0168 81

[6] Section On Complementary And Integrative Medicine (SCIM), Council on Children withDisabilities (CCD), American Academy of Pediatrics (AAP), Zimmer M, Desch L. (2012). Sensory integration therapies for children with developmental and behavioral disorders. Pediatrics. 2012; 129(6): 1186-9. PMid:22641765 https: //doi.org/10.1542/peds. 2012-0876

[7] Bronfenbrenner U, Morris PA. The Bioecological Model of Human Development. Handbook of Child Psychology. 2007; 1: 14. https://doi.org/10.1002/9780470147658. chpsy0114

[8] Uzunboylu H, Eris H, Ozcinar Z. Results of a citation analysis of knowledge management in education. British Journal of Educational Technology. 2011; 42(3): 527-38. https://doi.org/10.1111/j. 1467-8535.2009.01018.x

[9] Baranek GT. Autism during infancy: A retrospective video analysis of sensory-motor and social behaviors at 9-12 months of age. Journal of Autism and Developmental Disorders. 1999; 29(3): 213-24.

[10] Lin CK. Test of sensory integration function: User's manual (Chin)* Taipei, Taiwan: Psychological Corporation; 2004.

[11] Parham LD, Roley SS, May-Benson TA, et al. Development of a fidelity measure for research on the effectiveness of the Ayres Sensory
Integration intervention. Am J Occup Ther. 2011 Mar-Apr; 65(2): 133-42. PMid:21476360 https://doi .org/10.5014/ajot. 201 1.000745

[12] Ayres A. Sensory integration and learning disorders. Los Angeles, CA: Western Psychological Services; 1972.

[13] Ayres AJ. Sensory integration and the child. Los Angeles, CA: Western Psychological Services; 1979.

[14] Schaaf RC, Benevides T, Mailloux Z, et al. An intervention for sensory difficulties in children with autism: a randomized trial. J Autism Dev Disord. 2014 Jul; 44(7): 1493-506.

[15] Leong HM, Carter M, Stephenson J. Systematic review of sensory integration therapy for individuals with disabilities: Single case design studies. Research in Developmental Disability. 2015; 47: 34-51. PMid:26476485 https://doi.org/10.1016/j.ridd.2015.09 .022

[16] Highlights of changes from DSM-IV_TR to DSM-5. American Psychiatric Association, 2013. Available from: http://www.dsm5.o rg/about/Pages/DSMVOverview . aspx

[17] Byrne MW. Sensory processing disorder: any of a nurse practitioner's business. Journal of American Academy of Nurse Practionner. 2009; 1(6): 314-21. PMid:19527310 https://doi.org/10.1111/j.17 45-7599.2009.00417.x

[18] Lin CK, Wu HM, Wang HY, et al. Age as a factor in sensory integration function in Taiwanese children. Neuropsychiatric Disease and Treatment. 2013; 9: 995-1001. PMid:23940418 https: //doi.org/10.2147/NDT.S49514

[19] Bor W, McGee TR, Fagan AA. Risk factors for adolescent antisocial Behaviour: All Australian Longitudinal study. Australian \& New Zealand Journal of Psychiatry. 2004; 38(5): 365-729. PMid:15144516 https ://doi.org/10.1080/j.1440-1614.20 04.01365.x

[20] Sarno S, Erasmus LP, Lipp SW. Multisensory integration after traumatic brain injury: A reaction time study between pairing of vision, touch, and audition. Brain Injury. 2003; 17(5): 413-26. PMid:12745713 https://doi.org/10.1080/02699050310000 70161

[21] Van Hulle C, Lemery-Chalfant K, Goldsmith HH. Trajectories of Sensory Over-Responsivity from Early to Middle Childhood: Birth and Temperament Risk Factors. PLoS One. 2015; 10(6): e0129968. 
PMid:26107259 https://doi.org/10.1371/journal . pone.0 129968

[22] Wilbarger J, Gunnar M, Schneider M, et al. Sensory processing ininternationally adopted, post-institutionalized children. Journal of Child Psychology and Psychiatry. 2010; 51(10): 1105-14. PMid:20738449 https://doi.org/10.1111/j.1469-7610.2010.02255.x

[23] Liu BH, Huang YQ, Wang YL, et al. An epidemiological study of relationship between sensory integration dysfunction in preschool children and parental rearing behavior. Chinese Journal of Epidemiology (Chin). 2002; 23(z1): 114-6.

[24] Ren G, Wang YF, Gu YM, et al. Test report of children sensory integration assessing scale. Chinese Mental Health Journal (Chin). 1994; 4: $145-7$.

[25] Mailloux Z. An overview of Sensory Integration and Praxis Tests. American Journal of Occupational Therapy. 1990; 44(7): 589-94. PMid:2386185 https://doi .org/10.5014/ajot.44.7.589

[26] Smilkstein G. The family APGAR: a proposal for a family function test and its use by physicians. Journal of Family Practice. 1978; 6(6): 1231-9.

[27] Sun W, Yang GQ, Zhao J, et al. Studies on sensory integration dysfunction and the related influencing factors of 4-6 years old child in Kunshan region. Chinese Journal of Child Care (Chin). 2011; 19(12): 1130-3.

[28] Yu H, Wu Q, Gong YN. Relationship between behavior problems and sensory integration of preschool children. Maternal and Child Health Care of China (Chin). 2006; 21(20): 2811-13.

[29] Coster WJ, Haley SM. Conceptualization and measurement of disablement in infants and young children. Infants and Young Children. 1992; 4: 11-22. https://doi.org/10.1097/00001163-19920 4000-00004
[30] Morison SJ, Ames EW, Chisholm K. The development of children adopted from Romanian orphanages. Merrill-Palmer Quarterly. 1995; 41: 411-30.

[31] Marcovitch S, Cesaroni L, Roberts W, et al. Romanian adoptions: Parents' dreams, nightmares, and realities. Child Welfare. 1995; 74 993-1017.

[32] Morison SJ, Ellwood AL. Developmental milestones and intelligence. In Ames EW. The development of Romanian orphanage children adopted to Canada. Simon Fraser University, Burnaby, British Columbia. 1997.

[33] Provence S. Infants in institutions revisited. Zero to Three. 1989; 9 : $1-4$.

[34] Duncan G, Brooks-Gunn G. Consequences of growing up poor. New York, NY: Russell Sage Foundation; 1997.

[35] Lin SH, Cermak S, Coster WJ, et al. The relation between length of institutionalization and sensory integration in children adopted from Eastern Europe. American Journal of Occupational Therapy. 2005; 59: 139-47. PMid:15830613 https://doi .org/10.5014/ajot .59 .2 .139

[36] Schneide ML, Moore CF, Gajewski LL, et al. Sensory processing disorder in a primate model: evidence from a longitudinal study of prenatal alcohol and prenatal stress effects. Child Development. 2008; 79(1): 100-13. PMid:18269511 https://doi.org/10.111 $1 / j .1467-8624.2007 .01113 . x$

[37] Yuan HM, Wei YF, Yu XH, et al. Impact of delivery mode on children's sensory integration capacity for short and long term. Zhejiang Journal of Preventive Medicine (Chin). 2009; 21(6): 12-13, 16.

[38] Crepeau-Hobson MF. The relationship between perinatal risk factors and sensory processing difficulties in preschool children. Journal of Developmental and Physical Disabilities. 2009; 21(4): 315-328. https://doi.org/10.1007/s10882-009-9144-x 